\title{
Depression severity is correlated to the integrity of white matter fiber tracts in late-onset major depression
}

\author{
Rikke Beese Dalby ${ }^{\mathrm{a}, *}$, Jesper Frandsen ${ }^{\mathrm{b}}$, M. Mallar Chakravarty ${ }^{\mathrm{b}, \mathrm{c}}$, Jamila Ahdidan ${ }^{\mathrm{a}}$, Leif Sørensen ${ }^{\mathrm{d}}$, \\ Raben Rosenberg ${ }^{\mathrm{a}}$, Poul Videbech ${ }^{\mathrm{a}}$, Leif Østergaard ${ }^{\mathrm{b}}$ \\ ${ }^{a}$ Centre for Psychiatric Research, Aarhus University Hospital, Risskov, Skovagervej 2, DK-8240 Risskov, Denmark \\ ${ }^{b}$ Center of Functionally Integrative Neuroscience (CFIN), Aarhus University Hospital, Aarhus, Denmark \\ ${ }^{\mathrm{C}}$ PET Center, Aarhus University Hospital, Aarhus, Denmark \\ ${ }^{\mathrm{d}}$ Department of Neuroradiology, Aarhus University Hospital, Aarhus, Denmark
}

\section{A R T I C L E I N F O}

\section{Article history:}

Received 16 March 2010

Received in revised form 25 May 2010

Accepted 22 June 2010

\section{Keywords:}

Tractography

White matter hyperintensities

Fractional anisotropy

Apparent diffusion coefficient

Magnetization transfer ratio

\begin{abstract}
A B S T R A C T
Cerebral white matter lesions (WMLs) are believed to play an important role in a subset of major depression (MD). We aimed to describe the impact of WMLs on white matter pathways in MD using diffusion tensor imaging (DTI) and magnetization transfer imaging. As a novel approach, we used DTI tractography to assess pathways intersected by WMLs. We examined 22 patients with late-onset MD and 22 age- and gendermatched controls. Parametric maps of fractional anisotropy (FA), apparent diffusion coefficient (ADC), and magnetization transfer ratio (MTR) were obtained to describe tissue integrity. The association between depression severity and the tract-specific localization of WMLs was analyzed on a voxel-by-voxel basis. We showed a significant positive association between depression severity and fiber tracts intersected by WMLs in the left superior longitudinal fasciculus and the right uncinate fasciculus. In both groups, WMLs had significantly lower FA and MTR, and higher ADC than both the tracts they intersected and the normalappearing white matter (NAWM). In turn, the tracts intersected by WMLs had significantly lower FA and higher ADC than the NAWM. In conclusion, depression severity correlates with the tract-specific localization of WMLs. WMLs have a pronounced effect on white matter integrity in the pathways they intersect.
\end{abstract}

(c) 2010 Elsevier Ireland Ltd. All rights reserved.

\section{Introduction}

Imaging studies using T2-weighted magnetic resonance imaging (MRI) have reported an increased frequency of white matter hyperintensities, sometimes referred to as white matter lesions (WMLs), in major depression (MD), especially in late-onset and latelife MD (Herrmann et al., 2008; Videbech, 1997). As stated in the vascular depression hypothesis (Alexopoulos et al., 1997; Krishnan et al., 1997; Krishnan and McDonald, 1995), subcortical vascular changes may be an important contributor to WMLs, which in turn contribute to the pathogenesis in a subgroup of late-life MD by affecting moodregulating neuronal pathways, either by single, localized lesions or by an accumulation of lesions exceeding a certain threshold (Alexopoulos et al., 1997). The presence of subcortical WMLs in late-life depression has been associated with cognitive impairment (Austin et al., 2001; Goodwin, 1997; Herrmann et al., 2007), functional impairment (Steffens et al., 2002), poor treatment outcome (Alexopoulos et al., 2002, 2008; Chen et al., 2006; Hickie et al., 1995, 1997; Iosifescu et al., 2006; O'Brien et al., 1998; Simpson et al., 1998; Steffens et al., 2001;

\footnotetext{
* Corresponding author. Tel.: +45 7789 3608; fax: +45 77893619. E-mail address: rbdalby@dadlnet.dk (R.B. Dalby).
}

Taylor et al., 2003b), and a greater risk of subsequent dementia (Steffens et al., 2007). Although reports in the depression literature have found the WMLs to be mainly located in fronto-striatal circuits (Greenwald et al., 1998; MacFall et al., 2001; O'Brien et al., 2006; Sheline et al., 2008; Taylor et al., 2003a; Videbech et al., 2004), and in the basal ganglia (Videbech, 1997), the relation between lesion characteristics, their interference with specific white matter pathways, severity of symptoms, and disease remains largely unknown.

Recent advances in MRI technology, such as diffusion tensor imaging (DTI) and magnetization transfer imaging have facilitated the study of microstructural changes in neuropsychiatry. Magnetization transfer (MT) imaging is sensitive to water bound to macromolecules and has been demonstrated in post mortem studies to correlate with myelin content and axonal density (Chen et al., 2007; van Waesberghe et al., 1999). The method, quantified by the magnetization transfer ratio (MTR), which is a compound index of the exchange between free and protein-bound water protons pools, is regarded as superior to conventional MRI with respect to the detection and quantification of subtle white matter changes, e.g. in multiple sclerosis (Tofts et al., 2003). Studies using MT imaging in depression have revealed lower MTR in multiple white matter regions, including the fronto-striatal and limbic regions, and the genu and splenium of the corpus callosum (Gunning-Dixon et al., 2008; Kumar et al., 2004). 
DTI is based on the random thermal diffusion of water molecules (Basser et al., 1994; Pierpaoli et al., 1996) and is highly sensitive to changes in tissue microstructure, such as axonal injury (e.g. demyelination) and intracellular or extracellular edema, which may not be visualized with conventional MRI. Water diffusion is restricted by barriers such as cell membranes and myelin, which introduces a directional dependence termed anisotropy, quantified by means of an FA index (Beaulieu, 2009). The apparent diffusion coefficient (ADC) measures the magnitude of diffusion. DTI studies in MD have shown reduced FA in several white matter regions, primarily the prefrontal white matter regions, such as the superior frontal gyrus and anterior cingulate cortex (ACC), and in temporal regions, in elderly depressed subjects compared with controls (Bae et al., 2006; Nobuhara et al., 2006; Taylor et al., 2004; Yang et al., 2007). In general, DTI studies of affective disorders consistently identify reduced anisotropy in the frontal and temporal lobes and tracts of subjects with affective disorders relative to control subjects (Sexton et al., 2009). In remitted geriatric depression others have found the FA reductions to be more widespread and also to include the parietal and occipital regions as well as the basal ganglia (Yuan et al., 2007). In addition, changes in FA in distributed cerebral networks have been associated with failure to remit in geriatric depression (Alexopoulos et al., 2008; Taylor et al., 2008).

During the last decade, advances in DTI have facilitated the study of tract-specific measures of cerebral microstructural integrity in vivo, a technique known as tractography or fiber tracking (Basser et al., 2000) - see, for example, the review by Mori and van Zijl (2002). DTI tractography combines measurements of water diffusion direction in each image voxel to reconstruct the trajectory of fiber pathways, thus reflecting neural connectivity (Basser et al., 2000). The method has enabled virtual "dissections" of major white matter fascicles in the living brain (e.g., see Catani et al., 2002). Application of DTI tractography in depression has mainly been to define and describe anatomical connectivity in well-defined regions of interest, such as targets of deep brain stimulation (Gutman et al., 2009; Johansen-Berg et al., 2008).

We have previously reported on WMLs and vascular risk factors in late-onset MD (Dalby et al., 2010). In this study, we present a novel approach to examine the impact of WMLs on gray matter connectivity by using DTI tractography to reveal the pathways potentially affected by WMLs. To our knowledge, DTI tractography has not previously been implemented to assess the anatomical extent and impact of WMLs on white matter integrity, which we present here. The aim of our study was to combine tractography and measures of white matter integrity to determine the tract-specific localization of WMLs, and to characterize the WMLs as well as the tracts they intersect in patients with late-onset MD compared with non-depressed, age- and gendermatched controls. Specifically, we hypothesized that in late-onset MD: 1) WMLs co-locate with mood-regulating pathways to a higher extent in patients than in non-depressed controls, that 2) depression severity is associated with WMLs intersecting mood-regulating pathways, that 3) WMLs show impaired white matter integrity compared with the surrounding white matter, and that 4) fiber tracts intersected by WMLs show impaired white matter integrity compared with the surrounding white matter.

\section{Materials and methods}

\subsection{Subjects}

Whole-brain MRI data were acquired from 22 patients with lateonset, first-episode MD and 22 controls with no history of psychiatric illness. The two groups were matched for age and gender. A brief account of the clinical and socio-demographic data is given in Table 1. The patients were consecutively recruited from psychiatric hospitals in the County of Aarhus through referral to the Neuropsychiatric
Table 1

Socio-demographic and clinical characteristics of patients with late-onset major depression and non-depressed controls. MES = Bech-Rafaelsen Melancholia Scale.

\begin{tabular}{|c|c|c|c|c|c|c|}
\hline & \multicolumn{2}{|c|}{$\begin{array}{l}\text { Patients } \\
(n=22)\end{array}$} & \multicolumn{2}{|c|}{$\begin{array}{l}\text { Controls } \\
(n=22)\end{array}$} & \multicolumn{2}{|c|}{ Statistics } \\
\hline & Mean & S.D. & Mean & S.D. & $z$ & $P$ \\
\hline Age (years) & 57.4 & 4.6 & 59.2 & 7.3 & 0.5 & 0.64 \\
\hline Vascular risk factor score ${ }^{a}$ & 6.9 & 4.7 & 6.8 & 4.4 & 0.05 & 0.96 \\
\hline \multirow[t]{2}{*}{ MES score } & 16.5 & 5.8 & 0.3 & 0.8 & -5.9 & $<0.001^{\mathrm{b}}$ \\
\hline & $n$ & $\%$ & $n$ & $\%$ & & $P$ \\
\hline Gender & & & & & & 1.00 \\
\hline Male & 7 & 31.8 & 7 & 31.8 & & - \\
\hline Female & 15 & 68.2 & 15 & 68.2 & & - \\
\hline
\end{tabular}

a Composite vascular risk factor score as described in the Framingham Study (Wolf et al., 1991), comprising age, systolic blood pressure, antihypertensive treatment, diabetes, cigarette smoking, cardiovascular disease (coronary heart disease, cardiac failure, or intermittent claudication), atrial fibrillation, and left ventricular hypertrophia. b Significant results at $P<0.05$.

Clinic, Aarhus University Hospital, Risskov, Denmark, and from outpatient psychiatric clinics in the County of Aarhus, Denmark. All patients met the DSM-IV (American Psychiatric Association, 2000) criteria for major depression and the ICD-10 criteria (World Health Organization, 1993) for moderate to severe depression within 4 weeks of inclusion. Late onset was predefined as first onset of depressive symptoms after the age of 50 years. Controls were recruited through advertisement in local papers and went through a preliminary sorting for exclusion criteria (see below) in a thorough telephone screening procedure. At the inclusion all subjects were assessed with selected parts of the SCAN structured interview (Wing et al., 1998) and were rated for severity of depressive symptoms with the Bech-Rafaelsen Melancholia Scale (MES) (Bech, 2002), which is an extended version of the 6-item Hamilton Depression Scale. The patients underwent a clinical neuropsychological examination or alternatively the Mini-Mental State Examination (MMSE) test (Folstein et al., 1975), depending on clinical and practical circumstances (results not shown). All controls were screened with the MMSE test. Both patients and controls were thoroughly interviewed about their medical history and were screened for concurrent medical diseases and alcohol abuse by standard blood tests, including thyroid function, and they all underwent a neurological exam. According to the Edinburgh Handedness Inventory (Oldfield, 1971), all included subjects were right-handed, except for three patients and one control who were ambidextrous. Current medication and information on vascular risk factors, such as hypertension and smoking, was carefully recorded (Dalby et al., 2010), and a composite vascular risk score was calculated as defined in the Framingham Study (Wolf et al., 1991). Exclusion criteria for both groups were organic brain disease (e.g. former stroke, cerebral vascular malformations, or epilepsy), former brain injury, substance dependency, and conventional contraindications to undergo MRI scanning. Written informed consent was obtained from all study subjects, and the study was approved by the regional ethics committee on research and in accordance with the Declaration of Helsinki (World Medical Association, 2008).

\subsection{Scan protocol}

MRI scans were obtained with a whole-body 3T GE Signa HDx scanner (GE Medical Systems, Milwaukee, WI, USA). The MRI protocol consisted of an axial fast spoiled gradient echo (FSPGR) 3D T1-weighted sequence $(\mathrm{TE}=2.84 \mathrm{~ms}, \mathrm{TR}=6.64 \mathrm{~ms}, \mathrm{TI}=750 \mathrm{~ms}$, flip angle $=14$, field of view $($ FOV $)=240 \mathrm{~mm}$, matrix $256 \times 256$, slice thickness $=1.2 \mathrm{~mm}$, no gap), an axial T2-weighted fluid-attenuated inversion recovery (FLAIR) sequence $(\mathrm{TE}=120 \mathrm{~ms}, \mathrm{TR}=8650 \mathrm{~ms}, \mathrm{TI}=2250 \mathrm{~ms}$, FOV $=240 \mathrm{~mm}$, matrix $224 \times 256$, slice thickness $=5 \mathrm{~mm}$, gap $=1.5 \mathrm{~mm}$ ), an axial T2weighted sequence $(\mathrm{TE}=112 \mathrm{~ms}, \mathrm{TR}=5400 \mathrm{~ms}$, field of view $=$ 
$240 \mathrm{~mm}$, matrix $416 \times 416$, slice thickness $=5 \mathrm{~mm}$, gap $=1.5 \mathrm{~mm}$ ), and an axial DTI sequence $(\mathrm{TE}=79.7 \mathrm{~ms}, \mathrm{TR}=12500 \mathrm{~ms}$, flip angle $=14$, FOV $=240 \mathrm{~mm}$, matrix $128 \times 128$, slice thickness $=3.5 \mathrm{~mm}$, no gap, acquisition time approximately $7 \mathrm{~min}$ ). The DTI scan was performed using double spin echo single shot EPI with 26 gradient directions $\left(\mathrm{b}=1000 \mathrm{~s} / \mathrm{mm}^{2}\right)$ and $6 \mathrm{~b}=0 \mathrm{~s} / \mathrm{mm}^{2}$ acquisitions. The MT protocol consisted of two axial FSPGR 3D sequences ( TE $=6.9 \mathrm{~ms}$, TR $=33 \mathrm{~ms}$, flip angle $=5, \mathrm{FOV}=240 \mathrm{~mm}$, acquisition matrix $=256 \times 160$ interpolated to $256 \times 256$, slice thickness $=2.0 \mathrm{~mm}$ ); one with a MT saturation pulse and one without. The MT pulse was a Fermi-shaped pre-pulse with a nominal flip angle of $1100^{\circ}, 8 \mathrm{~ms}$ duration and $2400 \mathrm{~Hz}$ offset. The whole-body RF coil was used for transmission and is believed to be sufficiently homogenous for this application. We used comfortable, stabilizing foam pads to minimize subject head motion. Total acquisition time was approximately $50 \mathrm{~min}$.

\subsection{Image analysis}

The T1-weighted images were non-linearly transformed to match the MNI standard brain (Evans et al., 1994; Mazziotta et al., 2001). The subject-to-MNI space transformation was estimated using the ANIMAL algorithm (Collins et al., 1995; Robbins et al., 2004).

Diffusion tensors, FA, and ADC were calculated in each voxel of the brain according to the method of Le Bihan et al. (2001). MTR was calculated on a voxel-by-voxel basis as:

$M T R=\frac{M_{0}-M_{\mathrm{s}}}{M_{0}}$

where $M_{s}$ and $M_{0}$ represent signal intensities with and without the saturation pulse (Henkelman et al., 2001). The FA, ADC, and MTR data were co-registered with the $\mathrm{T} 1$ data in native space and were normalized to standard MNI space using the non-linear T1-to-MNI transformation, estimated using the ANIMAL algorithm, with a final voxel size of $1 \mathrm{~mm}^{3}$.

\subsection{White matter lesions}

In order to reduce the possible neuropathological heterogeneity in the lesion pool, we omitted periventricular WMLs from assessment and only included subcortical/deep WMLs (DWMLs). This decision was based on previous studies reporting distinct neuropathological (Fazekas et al., 1993; Thomas et al., 2002, 2003) as well as functional differences (Kim et al., 2008) between DWMLs and PVLs. In addition, the existing literature indicates a stronger association between DWMLs and depression (Krishnan et al., 2006), especially late-onset MD (O'Brien et al., 1996), compared with PVLs.

The DWMLs were identified as hyperintensities on the FLAIR images by an experienced neuroradiologist, blinded to subject status. Intra-rater reliability testing was not carried out. The T1- and T2weighted images were available for differential-diagnostic purposes. The identified lesions were manually labeled on the FLAIR images using Display software (McConnell Brain Imaging Centre, MNI, McGill University, Montreal, Quebec, Canada). The labeled lesions for each subject were resampled to a binary lesion mask in native space, each voxel presenting a value of 0 (= no lesion) or 1 (=lesion). An average map of lesion density based on the lesion masks in the patients and controls has been previously published (Dalby et al., 2010).

\subsection{Tractography procedure}

Tractography was performed in native space using in-house implementation of the fiber assignment with continuous tracking (FACT) algorithm as described by Mori et al. (Mori et al., 1999; Mori and van Zijl, 2002) with standard stopping criteria (FA<0.15 and angle between neighboring primary diffusion direction $<45^{\circ}$ ). The in- house developed software for visualization and tractography has been previously applied (Moller et al., 2007). Details on DTI acquisition parameters are given above. Tracking was initiated from the center of every voxel in the brain. As stated above, the binary image masks identifying DWMLs (lesion masks) were manually derived by labeling intensity hyperintensities on FLAIR image volumes for each subject. By applying the binary lesion masks to our tractography results from the DTI data, we identified the fiber tracts intersecting one or more DWMLs. The voxels for each of these fiber tracts were then retained as a separate image mask (secondary tractography masks). The resulting secondary tracking mask for each individual was saved as a binary mask, each voxel assigned a value of 0 (=no tract) or 1 (=tract intersecting one or more DWMLs). An illustration of the main steps in the tracking approach is given in Fig. 1. Before applying the binary lesion masks to our tractography results, each lesion was dilated one voxel in each direction to include the possible partial volume effects of border voxels.

The Supplementary Figs. SF1 and SF1 give an average map of the secondary tractography masks (i.e. the density of fiber tracts intersecting DWMLs) for the patients and controls, respectively. Selected slices of these average maps are presented in Fig. 2A and B.

For the voxel-based analyses, all individual secondary tracking masks were transformed to MNI standard space using the MRI-to-MNI space transformation, estimated using the T1-weighted data. These masks were subsequently blurred with a $4 \mathrm{~mm}$ full-width-halfmaximum Gaussian kernel to decrease spatial noise and smooth the data.

\subsection{Tissue characterization}

Classification of the MRI volume into gray and white matter was estimated from the T1-weighted images by using a neural networkbased approach (Cocosco et al., 2003). To avoid the effect of WMLs on white matter characteristics, an individual mask of normal-appearing white matter (NAWM) was made by subtracting the segmented DWMLs from the initial white matter mask in each subject and subsequently eroding the NAWM mask by one voxel in each direction to avoid partial volume effects with the WMLs, surrounding gray matter, and ventricles.

Median values of ADC, FA, and MTR were extracted from each individual's corresponding parametric maps in native space using the following ROIs: a) Lesion masks (DWMLs), b) secondary tracking masks, and c) NAWM masks. Prior to extraction, the DWMLs were also excluded from the secondary tracking masks to avoid the effect of lesions on tract characteristics.

Median values were chosen over mean values, as medians are less sensitive to extreme scores and are more appropriate for smaller sample sizes.

\subsection{Statistical analyses}

The median values of ADC, FA, and MTR, in each ROI were compared between groups with the Wilcoxon two-sample rank sum test (Mann-Whitney test) for continuous variables using Stata, release 9.2 (Stata Statistical Software, StataCorp LP, College Station, Texas, USA) with two-sided tests and a $5 \%$ level of significance. To compare ADC, FA, and MTR between regions, e.g. median FA in DWMLs compared with median FA in whole-brain NAWM, we used the Wilcoxon signed-rank sum test, which is a non-parametric counterpart to the paired $t$-test.

We used FMRISTAT (Worsley et al., 2002) to test for voxel-wise differences in ADC, FA, and MTR values between groups and to test for differences in the localization of tracts intersected by WMLs between patients and controls with one or more lesions, adjusted for age and gender. The effect of MES score on tractography outcome was studied using voxel-wise regression analyses. Resulting $t$-maps were examined 

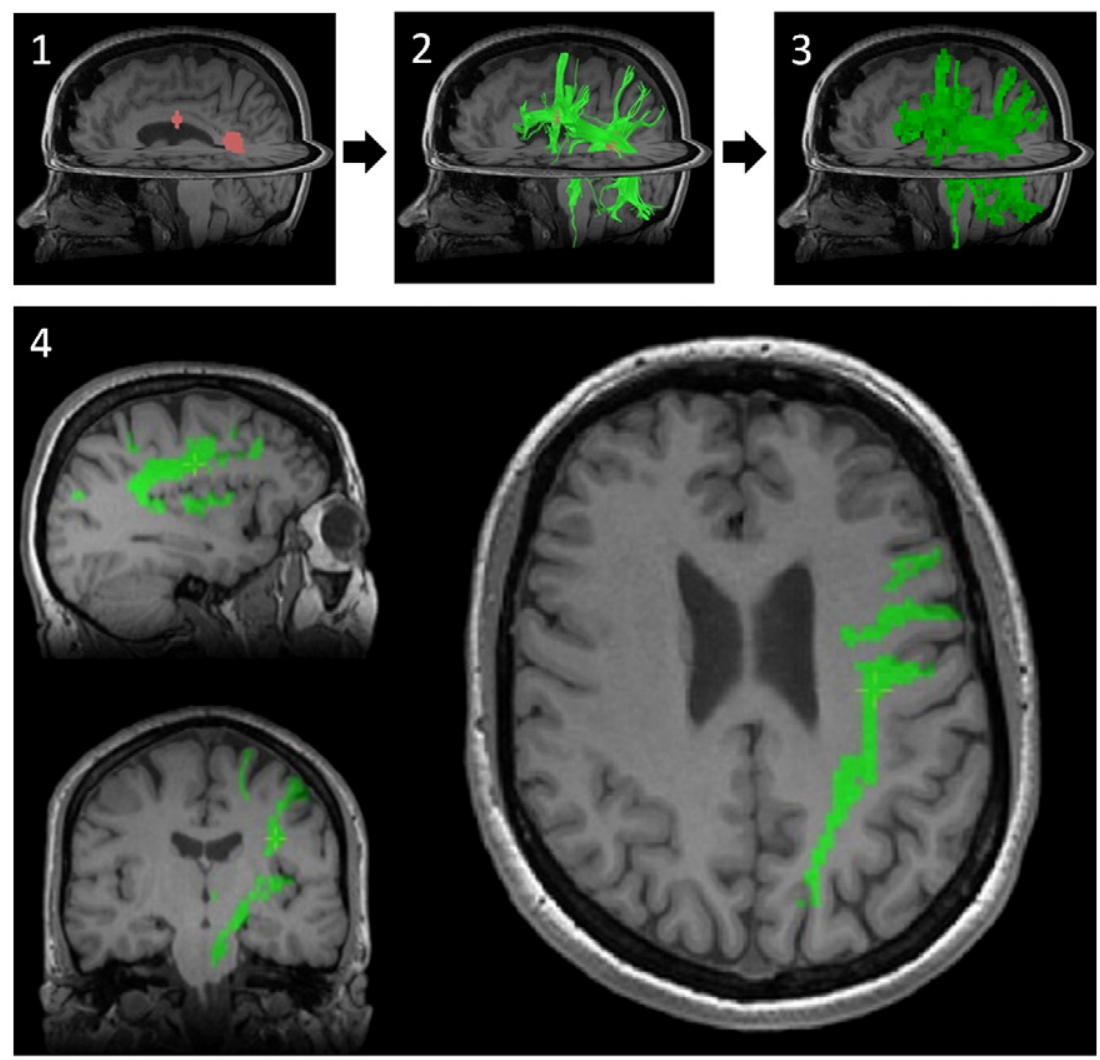

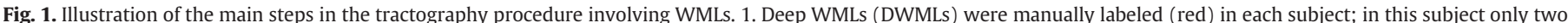

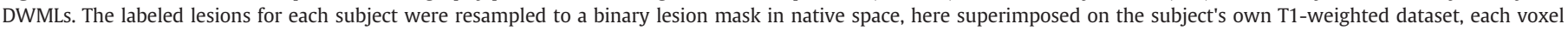

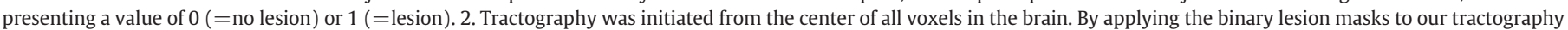

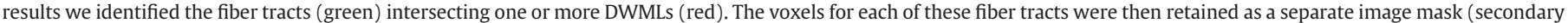

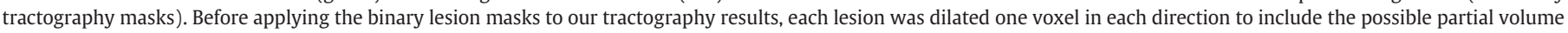

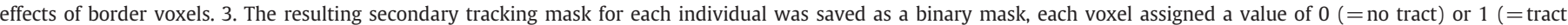

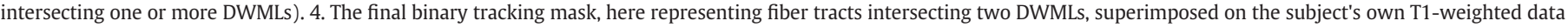
set.

for significant changes, including summary analyses of $t$-statistic images and correction for multiple comparisons, based on the 3D Gaussian random field theory (Worsley et al., 1996). We used the method of Cao (1999) to identify significant clusters, defined as a minimum number of 26 -connected voxels at $t<-3.17$ or $t>3.17(P<0.05)$. The resultant images were reviewed in Register (McConnell Brain Imaging Centre, MNI, McGill University, Montreal, Quebec, Canada), and the white matter tracts were anatomically evaluated according to the DTI-based white matter atlas by Mori et al. (2005).

\section{Results}

Patients and controls showed a similar composite vascular risk factor score (Table 1). Details on vascular risk factors and lesion load have been previously described (Dalby et al., 2010). We reported no significant difference in the number $[P=0.63]$ or volume $[P=0.65]$ of DWMLs between groups (data not shown).

\subsection{Tractography}

Overall, voxel-based analyses did not reveal any significant difference in the localization of fiber tracts intersected by DWMLs patients and controls $[P=0.37]$, adjusted for age and gender.

An average map of the secondary tracking masks in standard space was made for the patients and controls, respectively, to illustrate the distribution of trajectories affected by WMLs in the two groups (see Supplementary Figs. SF1 and SF2 for a full overview). Selected slices of these average maps are shown in the left panel of Fig. $2 \mathrm{~A}$ and $\mathrm{B}$. The slices were selected as they featured the areas with the greatest difference in the localization of tracts intersected by WMLs between groups. This difference is pointed out in the subtraction map in the adjacent right panel, which shows where more patients than controls had tracts intersected by WMLs. The subtraction map shows that both the frontal projections of the genu of the corpus callosum (Fig. 2A), as well as the opercular part of the right superior longitudinal fasciculus (SLF) (Fig. 2B), were intersected in up to 30\% more patients than controls. However, these apparent differences in localization did not reach statistical significance.

Post-hoc voxel-based analyses for depression severity (MES score) were only carried out for the patient group $(n=22)$, as the controls - as expected - scored 0 or very low on this scale (see Table 1 ). A significant positive association between higher MES score and secondary tractography masks, adjusted for age and gender, was found in two areas, as illustrated in Fig. 3A, the left operculum corresponding to the opercular part of the left SLF $[P=0.03]$, and $B$ ) the right superior temporal gyrus corresponding to the temporal projections of the right uncinate fasciculus $[P=0.04]$.

\subsection{Tissue characterization}

Voxel-based analysis did not reveal any significant areas with lower FA $[P=0.83]$, higher ADC $[P=0.90]$, or lower MTR $[P=0.94]$ in patients compared with controls.

Non-parametric testing of differences in median values of FA, ADC, and MTR in a) lesion masks (DWMLs), b) secondary tracking masks, and c) NAWM masks, respectively, showed no significant differences 

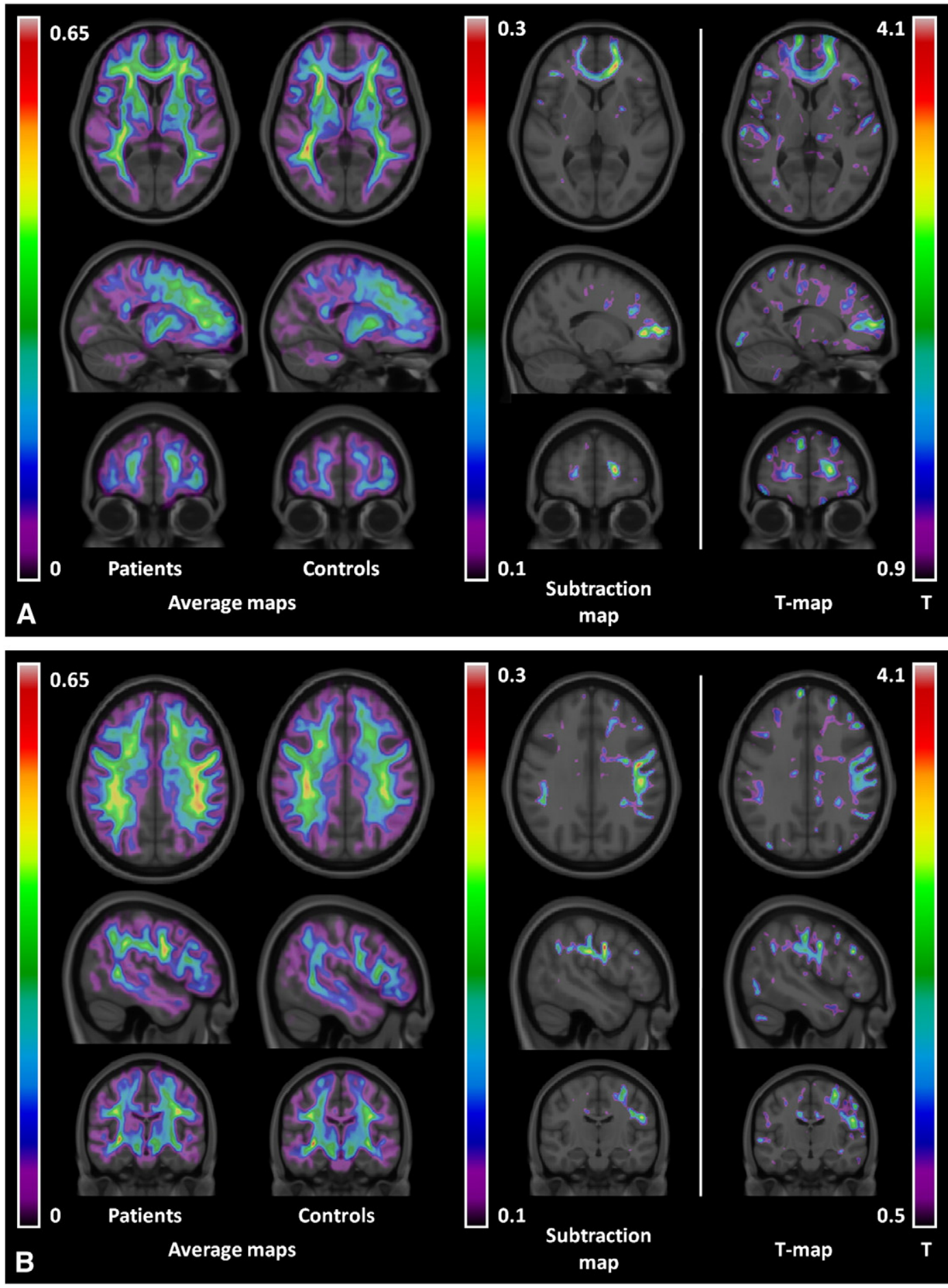

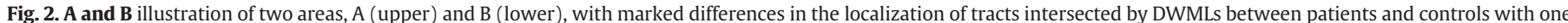

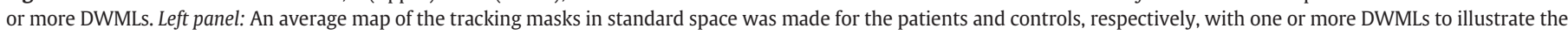

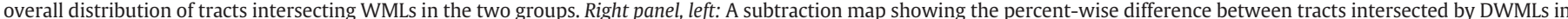

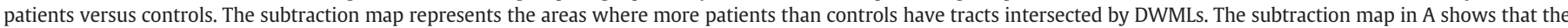

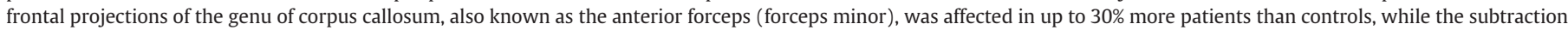

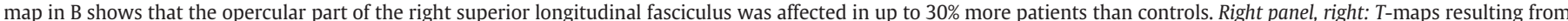

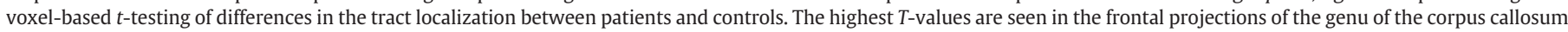
(A) and in the opercular section of the right superior longitudinal fasciculus (B), but did not reach statistical significance $(P>0.05)$. DWMLs $=$ deep white matter lesions.

between groups; results are summarized in Table 2. Because of the similar characteristics, the two groups were pooled for succeeding analyses. The right section of Table 2 shows the results from analyses of the pooled regional FA, ADC, and MTR for all subjects with one or more DWMLs regardless of subject status $(n=38)$. Paired non-parametric testing showed that DWMLs had significantly lower FA and MTR, and higher ADC than both the tracts they intersected and the whole-brain NAWM. In turn, the tracts intersected by DWMLs had significantly lower FA and higher ADC compared with the whole-brain NAWM; there was a trend towards significantly lower MTR $[P=0.10]$. 


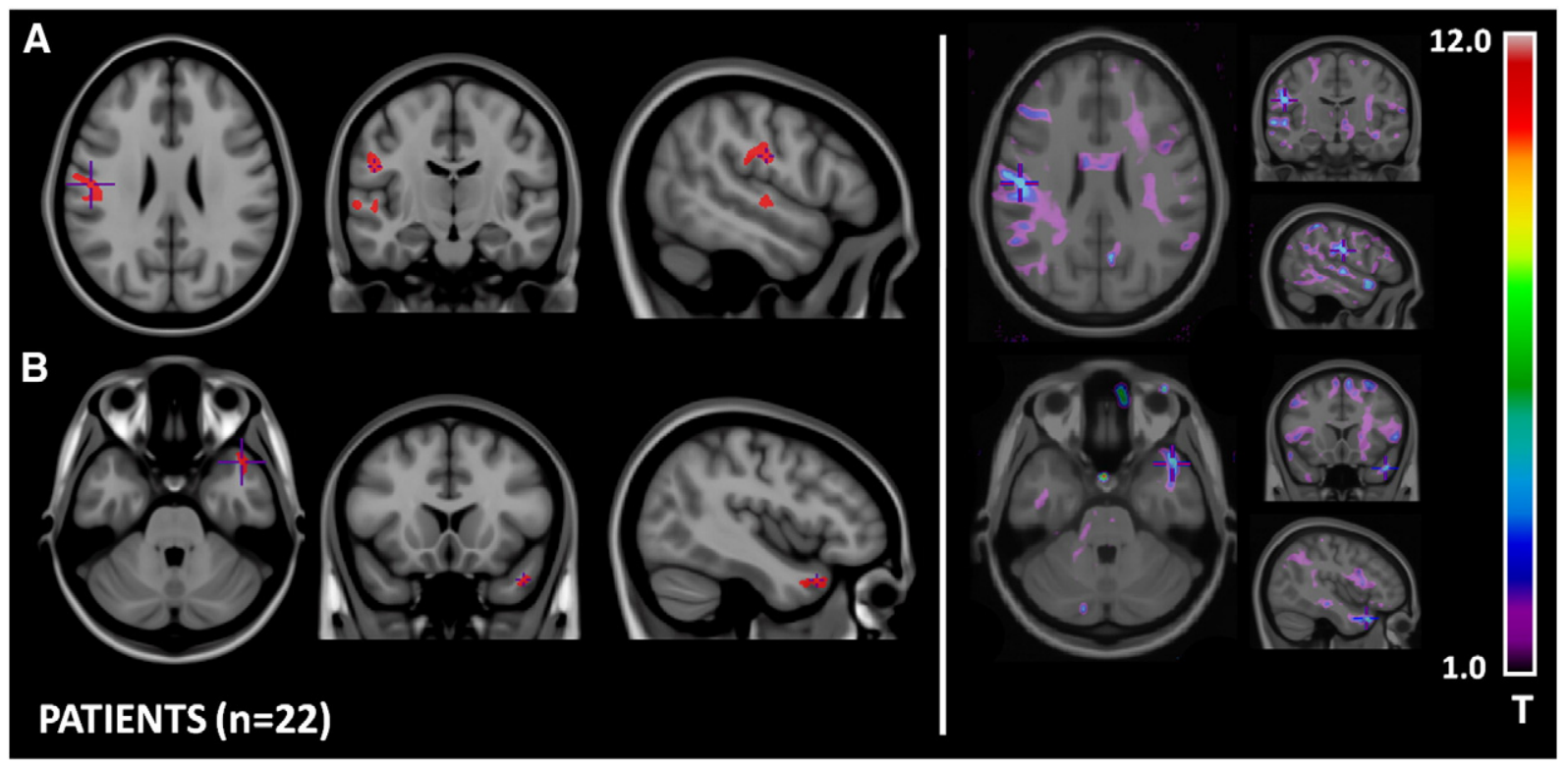

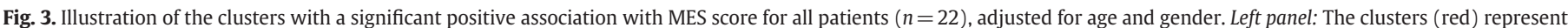

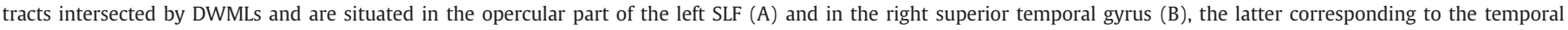

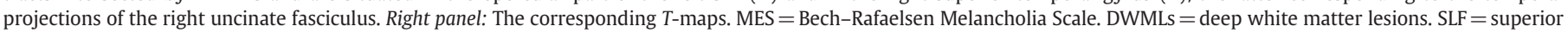
longitudinal fasciculus.

\section{Discussion}

In this study we combined an innovative DTI tractography approach with standard diffusion and magnetization transfer measures to assess the anatomical extent and impact of DWMLs on white matter fiber pathways in patients with late-onset MD compared with non-depressed, age- and gender-matched controls. The principal finding of our study is that DWMLs profoundly affect white matter integrity, measured by diffusion and magnetization transfer parameters, both within the lesion sites themselves and along the neuronal pathways they intersect, and do so in a similar manner in patients and controls. Although the overall tract-specific localization of WMLs did not differ between patients and controls, we showed that depression severity correlates with fiber tracts intersected by DWMLs in pathways involved in the regulation of mood and cognition.

\subsection{Tissue characterization}

While our measurements did not permit us to directly address the underlying pathoanatomical damage to fiber architecture, previous studies correlating MRI findings to post mortem studies suggest that WMLs may indeed cause widespread degenerative changes in both normal aging (Awad et al., 1986a; Fazekas et al., 2005) and disease (Schmierer et al., 2004; van Waesberghe et al., 1999). Neuropathological correlates of DWMLs are diverse and include arteriosclerosis, atrophic demyelination, enlarged perivascular spaces, and vascular

Table 2

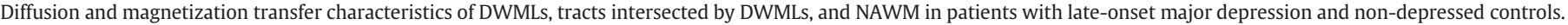

\begin{tabular}{|c|c|c|c|c|c|c|c|c|c|}
\hline & \multicolumn{6}{|c|}{ All subjects $(n=44)$} & \multicolumn{3}{|c|}{ Subjects with WMLs $(n=38)$} \\
\hline & \multicolumn{2}{|c|}{ Patients $(n=22)$} & \multicolumn{2}{|c|}{ Controls $(n=22)$} & \multicolumn{2}{|c|}{ Statistics } & \multirow[t]{2}{*}{ Comparison } & \multicolumn{2}{|c|}{ Statistics } \\
\hline & Median & $95 \% \mathrm{Cl}^{\mathrm{a}}$ & Median & $95 \% \mathrm{Cl}^{\mathrm{a}}$ & $z$ & $P$ & & $z$ & $P$ \\
\hline \multicolumn{10}{|l|}{$F A$} \\
\hline a) DWMLs ${ }^{b}$ & 0.33 & $0.32-0.34$ & 0.33 & $0.31-0.36$ & 0.40 & 0.69 & a versus $b$ & -5.26 & $<0.001$ \\
\hline b) Tracts $^{\text {b }}$ & 0.40 & $0.39-0.42$ & 0.42 & $0.41-0.44$ & 1.07 & 0.28 & a versus c & -5.33 & $<0.001$ \\
\hline c) NAWM & 0.43 & $0.42-0.44$ & 0.43 & $0.42-0.44$ & 0.21 & 0.83 & b versus c & -3.67 & $<0.001$ \\
\hline \multicolumn{10}{|c|}{$A D C\left(10^{-3} \mathrm{~mm}^{2} / \mathrm{s}\right)$} \\
\hline a) DWMLs ${ }^{b}$ & 0.79 & $0.78-0.82$ & 0.83 & $0.80-0.85$ & 1.42 & 0.15 & $a$ versus $b$ & 5.36 & $<0.001$ \\
\hline b) Tracts $^{\text {b }}$ & 0.74 & $0.71-0.77$ & 0.75 & $0.73-0.77$ & 0.07 & 0.94 & a versus c & 5.36 & $<0.001$ \\
\hline c) NAWM & 0.69 & $0.67-0.72$ & 0.73 & $0.71-0.75$ & 0.78 & 0.44 & b versus c & 4.87 & $<0.001$ \\
\hline \multicolumn{10}{|l|}{ MTR } \\
\hline a) DWMLs ${ }^{\text {b }}$ & 0.66 & $0.63-0.69$ & 0.62 & $0.60-0.63$ & -1.57 & 0.12 & $a$ versus $b$ & -4.31 & $<0.001$ \\
\hline b) $\operatorname{Tracts}^{\mathrm{b}}$ & 0.68 & $0.65-0.70$ & 0.63 & $0.60-0.65$ & -0.95 & 0.34 & a versus c & -4.57 & $<0.001$ \\
\hline c) NAWM & 0.68 & $0.65-0.70$ & 0.63 & $0.61-0.66$ & -1.55 & 0.12 & b versus c & -1.67 & 0.10 \\
\hline
\end{tabular}

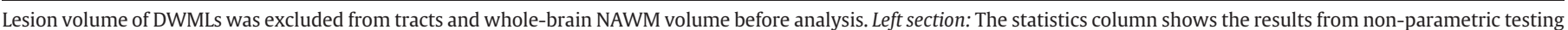

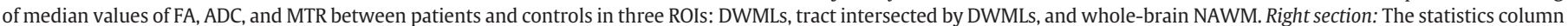

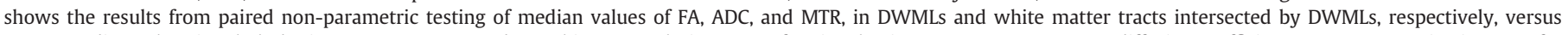

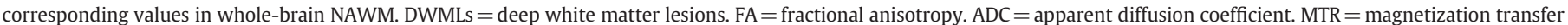
ratio. $\mathrm{NAWM}=$ normal-appearing white matter.

a Approximated 95\% confidence interval (CI) after McGill et al. (1978).

b Only subjects with WMLs (17 patients and 21 controls). 
ectasia (Theobald et al., 2000). Microvascular disturbances ultimately resulting in cerebral ischemia have been proposed as playing a major role in the pathogenesis of WMLs. However, the causes of WMLs are incompletely understood, and may be the result of several mechanisms resulting in local increased brain water content as reflected in the T2-weighted MRI images (Pantoni and Garcia, 1995). The presence and severity of WMLs increase with age and have been shown to correlate with vascular risk factors, such as hypertension and smoking (de Leeuw et al., 2002; Longstreth et al., 2005). In agreement with previous findings by Taylor et al. (2001), we were not able to demonstrate any difference between patients and controls in diffusion characteristics of the DWMLs, and this finding recurred in the tracts intersected by DWMLs. The same was applicable for the MTR, in support of a similar origin of lesions in patients and controls, which may ultimately reflect the equal vascular risk factor score between groups (Table 1 ).

A novel finding is the observed significant changes in diffusion parameters in the fiber tracts intersected by DWMLs, compared with the DWMLs themselves and the surrounding NAWM in both groups. Although previous studies of late-life MD have reported microstructural abnormalities in NAWM in depressed patients compared with healthy controls (Kumar et al., 2004), even after excluding visible WMLs (Shimony et al., 2009), no previous literature has described the tract-specific impact of the WMLs on brain microstructure in vivo as presented here. In comparison, the observation of changes in ADC, FA, and MTR in DWMLs is in agreement with several previous studies of late-life depression (Fazekas et al., 2005; Filippi, 2001; Gouw et al., 2008; Shimony et al., 2009; Tanabe et al., 1999; Taylor et al., 2001). Due to the relative changes between DWMLs, the tracts they intersect, and the NAWM, our results suggest a pronounced effect of DWMLs on white matter integrity, most profoundly localized to the lesion sites themselves, but also - albeit to a lesser extent - in the tracts they intersect. However, the cross-sectional design of our study does not allow us to conclude on any causal link between the DWMLs and the observed changes in white matter integrity of the tracts they intersect. We have previously reported smoking as a major contributor to the number and volume of DWMLs (Dalby et al., 2010). Smoking is considered a risk factor for WMLs, possibly on the basis of long-term damaging effects attributed to atherosclerosis and oxidative stress, mediated by inflammatory processes and nicotine-induced free radicals (Jane-Llopis and Matytsina, 2006). Cigarette smoking has been shown to be an independent predictor of worsening white matter grade in the elderly (Longstreth et al., 2005). However, a recent study suggested that healthy adults with low exposure to cigarette smoking showed increased microstructural integrity of the white matter compared with either no or high exposure (Paul et al., 2008).

Surprisingly, our patients with late-onset MD did not show greater microstructural abnormalities, measured as voxel-wise changes in FA, $\mathrm{ADC}$, or MTR, in any region, including the fronto-striatal regions, compared with the controls. This is in contrast to previous findings (Bae et al., 2006; Gunning-Dixon et al., 2008; Nobuhara et al., 2006; Taylor et al., 2004). Several explanations apply to our negative findings; firstly, our choice of voxel-based analysis generally carry lower statistical power than ROI analyses, which are used in most previous studies (Bae et al., 2006; Nobuhara et al., 2006; Taylor et al., 2004). Secondly, our sample size was lower than in two of the mentioned studies (Bae et al., 2006; Gunning-Dixon et al., 2008), thereby introducing the risk of type 2 errors. However, in these previous studies no - or only sparse - information on the concurrent presence and distribution of WMLs and vascular risk factors across groups were provided. As increased WMLs volumes have been associated with lower FA and higher ADC values, indicative of widespread effects on microstructural integrity (Taylor et al., 2007), and as WMLs are generally associated with the presence of vascular risk factors (Awad et al., 1986b; Breteler et al., 1994; Fazekas et al.,
1993; Liao et al., 1997), we therefore speculate that our negative findings may be a consequence of an equal lesion load and similar composite vascular risk factor scores between groups (Dalby et al., 2010).

\subsection{Fiber tract localization}

Interestingly, we were not able to show any significant difference in the overall localization of fiber tracts intersected by DWMLs in patients compared with controls, which contradicts our first hypothesis, based on previous literature on the localization of WMLs (Herrmann et al., 2008; Videbech, 1997). The main reason for this inconsistency could be the limited power of our study due to a relatively small sample size, thus introducing the risk of a type 2 error. The age of our sample is lower than in most previous studies of lateonset MD. We chose a lower cut-off at 50 years to pass the female menopause. On the one hand, this may be a strength to our study, thereby including relatively younger patients with different degrees of vascular risk factors. On the other hand, a relatively younger sample may dilute isolated findings in an older population. In addition, while findings in previous studies may reflect the impact on brain microstructure of recurrent episodes, we chose to include only patients with first-episode MD in order to reduce heterogeneity in the course of illness. Furthermore, our patients and controls had a similar lesion load and a similar vascular risk factor score, which improves the comparability between the two groups. The similar vascular risk factor score between groups may reflect the intentional inclusion of controls presenting with vascular risk factors, such as hypertension, in order to match the vascular profile of our patient group. Finally, our tractography findings emphasize the fact that WMLs may affect a given pathway anywhere along its course, i.e. disruption of a pathway is not necessarily a result of primary damage to a specific brain region, which makes it difficult to directly compare findings from tractography and lesion studies.

\subsection{Depression severity}

In the patients with late-onset MD we showed a significant positive association between depression severity (higher MES score) and having tracts intersected by DWMLs in the opercular part of the left SLF and the temporal projections of the right uncinate fasciculus (Fig. 3). These tract localizations are coincident with our group's previous findings regarding the localization of DWMLs in late-onset MD (Dalby et al., 2010). In general, DWMLs have been associated with severity of depression, severity of cognitive impairment, risk and outcome in MD (Kim et al., 2008). For example, MacFall et al. (2001) have found that severity of late-life depression was correlated with lesions in the medial orbital region. The uncinate fasciculus is considered part of the limbic system and is attributed to the functional aspects of emotion, behavior, and memory (Drevets et al., 2008). Our findings thus suggest an important role for the uncinate fasciculus in $\mathrm{MD}$, in consistency with our second hypothesis. The SLF is a long association fiber bundle interconnecting areas within the frontal, parietal, occipital, and temporal lobes (Catani et al., 2002; Heimer, 1995; Makris et al., 2005). The human SLF can be segmented into 4 subregions: SLF I, II, III, and the arcuate fasciculus, which in turn play an important role in a variety of neurological or cognitive functions such as working memory, somatosensory responses, spatial attention, language, and motor behavior/function (Makris et al., 2005). Many of these functions are compromised to various degrees in late-life depression (Butters et al., 2004; Sheline et al., 2006). Some of the functions are lateralized, such as the attention to sensory stimuli which in humans primarily activates the prefrontal and superior parietal cortex in the right hemisphere (Pardo et al., 1991). Newer research indicates a potential role for the SLF in volition (Haggard, 2008), which is often impaired in MD. Indeed, the disturbances in 
mood and cognitive functions in MD may result from a relative imbalance among several affected connections rather than disruption of a single pathway (Mayberg, 1997), in accordance with the vascular depression hypothesis (Alexopoulos et al., 1997). Thus, our findings imply an important role for tract-specific localization of DWMLs on the severity of symptoms in late-onset MD rather than a categorization of patients or controls. The clinical implications of these findings are intriguing, as our tractography approach provides more exact anatomical information of the tracts and circuitries affected by WMLs.

The clinical relevance of correlations between state variables such as depression severity and trait variables such as structural findings, including WMLs, is a matter of debate. Clinical variables often fluctuate over shorter time intervals than structural changes and may in basic terms be difficult to correlate. We acknowledge that it may be difficult to correlate observed symptoms with underlying anatomy. In our study, the patients were moderately to severely depressed, and the severity justified admission to a psychiatric hospital or out-patient psychiatric clinic. We assumed that rapid changes in MES score for these patients shortly after referral and inclusion would be unlikely. Our patients have an average MES score equaling a moderate depression (Table 1), declining towards recovery. Since our study design was cross-sectional, and the patients might have had a higher MES score (i.e. more severe depression) at a previous point before referral, this would only increase the significance and thereby strengthen the association between higher MES score and tractography findings. Medication is another confounder which may over time confuse depression severity rating with treatment response rates. Unfortunately, unmedicated patients were for practical and ethical reasons difficult to attain in our combined inand out-patient setting.

\subsection{Methodological issues}

Our tractography approach raises some important methodological issues, first of all the question of whether tracking through WMLs is reasonable. Several studies have emphasized the heterogeneity of WMLs (Barkhof and Scheltens, 2002; Gouw et al., 2008; Spilt et al., 2006). The neuropathological correlates of WMLs are diverse and depend on lesion severity (Fazekas et al., 1993). Consequently, WMLs may affect tracts in various degrees, from minimal structural damage to total disconnection; if the latter was true in our study population, the substantial load of WMLs in our patients and controls would cause massive neurological symptoms, which was not the case. In addition, the tracking algorithm employed the standard stopping criteria of $\mathrm{FA}<15$ which is well below the measured median FA value of the DWMLs (Table 2). However, we cannot preclude that some lesions may totally disconnect a tract, or that localized edema may change the course of a tract, thereby terminating or altering the tracking in this area, and consequently underestimate the generated tracts. To account for this possibility our tractography protocol included the step of adding a voxel in each direction around a given lesion prior to the tracking, in the presumption that less affected surrounding tracts would be tracked instead. We used a deterministic tracking method, and application of voxel-based analysis to this kind of tractography data does not account for the spatial dependency in the tractography procedures, i.e. the likelihood of a voxel neighboring a tracked voxel also being tracked may be greater than for a voxel far away from this area. Accounting for this co-dependency calls for a future probabilistic approach. Nonetheless, voxel-based analysis is useful in exploratory approaches, where white matter changes are diffuse (Catani, 2006).

There are some limitations of our study, mainly related to the use of DTI tractography (Assaf and Pasternak, 2008). DTI acquisition parameters were chosen to accommodate both appropriate signal-tonoise ratio (SNR) and clinically acceptable total scan time. An isotropic "gold standard" spatial resolution (e.g. $2.5 \times 2.5 \times 2.5 \mathrm{~mm}^{3}$ ) was not possible in our scan protocol $\left(1.88 \times 1.88 \times 3.5 \mathrm{~mm}^{3}\right)$, but the resulting voxel size in our sample was actually smaller than in the isotropic example (Jones et al., 2002). We used 26 gradient directions for DTI, and according to Jones (2004) the advantage in reliable determination of tensor direction after 25-30 directions is minimal. Tractography is most sensitive to major fiber bundles, while small or tortuous paths are more challenging to track, making the method susceptible to false negatives. In addition, a pitfall of the diffusion tractography is that the calculated trajectory of the fiber may fail to follow the true fiber tract trajectory because of small uncertainties in the determination of the primary diffusion direction due to inherently noisy DTI, crossing fibers (Basser et al., 2000; Le Bihan, 2003), and partial volume effects (Alexander et al., 2001). Also, the tracking procedure itself may influence the results, for example regarding the choice of seed voxels. In our approach, tracking was initiated from all voxels within the brain, and only tracking results that penetrated the voxels of interest (i.e. the DWMLs) were kept. This is opposed to approaches mainly based on anatomically well-defined tracts which may impose limitations on the discovery on new or less explored tracts (Mori and van Zijl, 2002).

We chose to compare tract and lesion characteristics with NAWM. Indeed, the term NAWM should be used with caution, as MRI characteristics vary in different brain regions and in different acquisition protocols, depending on regional fiber orientation and organization. For example, highly structured white matter areas such as the long association fibers and commissural bundles would per definition have higher FA and MTR values than less organized white matter areas or white matter in areas with many crossing fibers, and the impact of WMLs may therefore vary relatively to the anatomical localization. Consequently, perfectly matching white matter areas for comparison analyses are very difficult to attain. In this study tracking was initiated from all voxels within the brain. Thus, our approach did not allow the usual ROI approach with pre-chosen start and end points to outline major fiber tracts. Therefore we were not able to define anatomical "control tracts", but chose the NAWM for comparison instead. Importantly, as we segmented only DWMLs, thereby permitting PVLs in the NAWM masks, we cannot preclude a possible effect of PVLs on whole-brain white matter characteristics. However, as literature reports decreased FA and increased ADC in such PVLs (Bastin et al., 2009), this only strengthens our findings of reduced FA and ADC in the segmented DWMLs and intersecting pathways compared with the NAWM.

We used a manual segmentation method for the WMLs, which allowed us to distinguish between DWMLs and PVLs. While several (semi)automated techniques exist for the classification of WMLs, many of these techniques are not yet optimal (Kim et al., 2008) and their applicability to new datasets from different scanner models are unclear. The multiple sclerosis imaging community have developed advanced techniques with respect to the classification of WMLs, but most of the algorithms used integrate prior statistical knowledge based on the expected spatial distribution of these lesions, which would not hold for the classification of WMLs in MD. The T2-weighted FLAIR sequence used for identification and segmentation of WMLs had a slice thickness of $5 \mathrm{~mm}$ and a $1.5-\mathrm{mm}$ gap between slices, thereby introducing the risk of sampling errors with respect to the definition of WMLs. However, these parameters were consistent through the data, and the slice thickness and gap were adopted to increase SNR, diminish cross-talk, and keep an acceptable acquisition time. A major strength of our study is the use of 3T MRI, which allows better spatial resolution and increased SNR than $1.5 \mathrm{~T}$ MRI, thereby improving the detection of more subtle white matter changes.

In conclusion, we here present a novel approach using DTI tractography to describe the localization and impact of DWMLs on gray matter connectivity in late-onset major depression and nondepressed controls. Our results suggest that DWMLs have a marked effect on measures of white matter integrity both locally within the lesion site and along the neuronal pathways they intersect. Although 
no overall difference in the tract-specific localization of WMLs was found between groups, depression severity correlated significantly with fiber tracts affected by DWMLs in pathways involved in mood and cognition. The use of DTI tractography as a segmentation tool for mapping cerebral pathways affected by WMLs allows future integrative approaches, combining cognitive and microstructural measures to address the functional impact of WMLs on tissue integrity in neuropsychiatric disease.

\section{Acknowledgments}

The authors wish to thank consultant Elisabeth Tehrani, PhD, Neuropsychiatric Clinic, Aarhus University Hospital, Risskov, Denmark for clinical assistance, Leslie Foldager, Centre for Psychiatric Research, Aarhus University Hospital, Risskov, Denmark for statistical support, and Sune Nørhøj Jespersen, PhD, Peter Vestergaard-Poulsen, PhD, Ryan Sangill, PhD, Dora Zeidler and Michael Geneser, CFIN, Aarhus University, Aarhus, Denmark for technical advice and assistance regarding the MRI scans.

The study was supported by: the Danish National Research Foundation, the Danish Medical Research Council, the Research Fund of the Central Denmark Region, the Eli Lilly Psychiatric Research Foundation, the A.P. Møller Foundation for the Advancement of Medical Science, the Eli and Egon Larsen Foundation, the Wørzner Foundation, the AstraZeneca Travel Grant for Danish Psychiatrists, the Danish Psychiatric Society Travel and Educational Grant, the Helga and Peter Korning Foundation, the Jacob and Olga Madsen Foundation, the Dr. Poul M. Færgeman Foundation, the Dr. K. Rasmussen Foundation, the Eilif Trier-Hansen and Ane Trier-Hansen Foundation, the Fund for Research in Mental Illness, Psychiatric Research Fund of 1967 and the Einar Geert-Jørgensen and Ellen Geert-Jørgensen Research Fund.

\section{Appendix A. Supplementary data}

Supplementary data associated with this article can be found, in the online version, at doi:10.1016/j.pscychresns.2010.06.008.

\section{References}

Alexander, A.L., Hasan, K.M., Lazar, M., Tsuruda, J.S., Parker, D.L., 2001. Analysis of partial volume effects in diffusion-tensor MRI. Magnetic Resonance in Medicine 45, 770-780.

Alexopoulos, G.S., Meyers, B.S., Young, R.C., Campbell, S., Silbersweig, D., Charlson, M., 1997. 'Vascular depression' hypothesis. Archives of General Psychiatry 54, 915-922.

Alexopoulos, G.S., Kiosses, D.N., Choi, S.J., Murphy, C.F., Lim, K.O., 2002. Frontal white matter microstructure and treatment response of late-life depression: a preliminary study. The American Journal of Psychiatry 159, 1929-1932.

Alexopoulos, G.S., Murphy, C.F., Gunning-Dixon, F.M., Latoussakis, V., Kanellopoulos, D., Klimstra, S., Lim, K.O., Hoptman, M.J., 2008. Microstructural white matter abnormalities and remission of geriatric depression. The American Journal of Psychiatry 165, 238-244.

American Psychiatric Association, 2000. Diagnostic and Statistical Manual of Mental Disorders, 4. ed. American Psychiatric Association, Washington, DC. text rev.

Assaf, Y., Pasternak, O., 2008. Diffusion tensor imaging (DTI)-based white matter mapping in brain research: a review. Journal of Molecular Neuroscience 34, 51-61.

Austin, M.P., Mitchell, P., Goodwin, G.M., 2001. Cognitive deficits in depression: possible implications for functional neuropathology. The British Journal of Psychiatry 178, 200-206.

Awad, I.A., Johnson, P.C., Spetzler, R.F., Hodak, J.A., 1986a. Incidental subcortical lesions identified on magnetic resonance imaging in the elderly II. Postmortem pathological correlations. Stroke 17, 1090-1097.

Awad, I.A., Spetzler, R.F., Hodak, J.A., Awad, C.A., Carey, R., 1986b. Incidental subcortical lesions identified on magnetic resonance imaging in the elderly. I. Correlation with age and cerebrovascular risk factors. Stroke 17, 1084-1089.

Bae, J.N., MacFall, J.R., Krishnan, K.R., Payne, M.E., Steffens, D.C., Taylor, W.D., 2006. Dorsolateral prefrontal cortex and anterior cingulate cortex white matter alterations in late-life depression. Biological Psychiatry 60, 1356-1363.

Barkhof, F., Scheltens, P., 2002. Imaging of white matter lesions. Cerebrovascular Diseases 13 (Suppl 2), 21-30

Basser, P.J., Mattiello, J., LeBihan, D., 1994. MR diffusion tensor spectroscopy and imaging. Biophysical Journal 66, 259-267.

Basser, P.J., Pajevic, S., Pierpaoli, C., Duda, J., Aldroubi, A., 2000. In vivo fiber tractography using DT-MRI data. Magnetic Resonance in Medicine 44, 625-632.
Bastin, M.E., Clayden, J.D., Pattie, A., Gerrish, I.F., Wardlaw, J.M., Deary, I.J., 2009 Diffusion tensor and magnetization transfer MRI measurements of periventricular white matter hyperintensities in old age. Neurobiology of Aging 30, 125-136.

Beaulieu, C., 2009. The biological basis of diffusion anisotropy. In: Johansen-Berg, H., Behrens, T.E.J. (Eds.), Diffusion MRI: From Quantitative Measurement to In-vivo Neuroanatomy. Academic Press, pp. 105-126.

Bech, P., 2002. The Bech-Rafaelsen Melancholia Scale (MES) in clinical trials of therapies in depressive disorders: a 20-year review of its use as outcome measure. Acta Psychiatrica Scandinavica 106, 252-264.

Breteler, M.M., van Swieten, J.C., Bots, M.L., Grobbee, D.E., Claus, J.J., van den Hout, J.H., van, H.F., Tanghe, H.L., de Jong, P.T., van, G.J., 1994. Cerebral white matter lesions, vascular risk factors, and cognitive function in a population-based study: the Rotterdam Study. Neurology 44, 1246-1252.

Butters, M.A., Whyte, E.M., Nebes, R.D., Begley, A.E., Dew, M.A., Mulsant, B.H., Zmuda, M.D., Bhalla, R., Meltzer, C.C., Pollock, B.G., Reynolds III, C.F., Becker, J.T., 2004. The nature and determinants of neuropsychological functioning in late-life depression. Archives of General Psychiatry 61, 587-595.

Cao, J., 1999. The size of the connected components of excursion sets of $\mathrm{x} 2$, $\mathrm{T}$ and $\mathrm{F}$ fields. Advances in Applied Probability 31, 579-595.

Catani, M., 2006. Diffusion tensor magnetic resonance imaging tractography in cognitive disorders. Current Opinion in Neurology 19, 599-606.

Catani, M., Howard, R.J., Pajevic, S., Jones, D.K., 2002. Virtual in vivo interactive dissection of white matter fasciculi in the human brain. Neuroimage 17, 77-94.

Chen, P.S., McQuoid, D.R., Payne, M.E., Steffens, D.C., 2006. White matter and subcortical gray matter lesion volume changes and late-life depression outcome: a 4-year magnetic resonance imaging study. International Psychogeriatrics 18 $445-456$.

Chen, J.T., Kuhlmann, T., Jansen, G.H., Collins, D.L., Atkins, H.L., Freedman, M.S. O'Connor, P.W., Arnold, D.L., 2007. Voxel-based analysis of the evolution of magnetization transfer ratio to quantify remyelination and demyelination with histopathological validation in a multiple sclerosis lesion. Neuroimage 36 $1152-1158$.

Cocosco, C.A., Zijdenbos, A.P., Evans, A.C., 2003. A fully automatic and robust brain MRI tissue classification method. Medical Image Analysis 7, 513-527.

Collins, D.L., Holmes, C.J., Peters, T.M., Evans, A.C., 1995. Automatic 3-D model-based neuroanatomical segmentation. Human Brain Mapping 3, 190-208.

Dalby, R.B., Chakravarty, M.M., Ahdidan, J., Sorensen, L., Frandsen, J., Jonsdottir, K.Y. Tehrani, E., Rosenberg, R., Ostergaard, L., Videbech, P., 2010. Localization of whitematter lesions and effect of vascular risk factors in late-onset major depression. Psychological Medicine 40, 1389-1399.

de Leeuw, F.E., de Groot, J.C., Oudkerk, M., Witteman, J.C., Hofman, A., van, G.J., Breteler, M.M., 2002. Hypertension and cerebral white matter lesions in a prospective cohort study. Brain 125, 765-772.

Drevets, W.C., Price, J.L., Furey, M.L., 2008. Brain structural and functional abnormalities in mood disorders: implications for neurocircuitry models of depression. Brain 213 93-118.

Evans, A.C., Collins, D.L., Mills, S.R., Brown, E.D., Kelly, R.L., Peters, T.M., 1994. 3D statistical neuroanatomical models from 305 MRI volumes. Proceedings of the 1993 IEEE Nuclear Science Symposium \& Medical Imaging Conference. IEEE, San Francisco, CA, USA, pp. 1813-1817.

Fazekas, F., Kleinert, R., Offenbacher, H., Schmidt, R., Kleinert, G., Payer, F., Radner, H., Lechner, H., 1993. Pathologic correlates of incidental MRI white matter signal hyperintensities. Neurology 43, 1683-1689.

Fazekas, F., Ropele, S., Enzinger, C., Gorani, F., Seewann, A., Petrovic, K., Schmidt, R., 2005. MTI of white matter hyperintensities. Brain 128, 2926-2932.

Filippi, M., 2001. In-vivo tissue characterization of multiple sclerosis and other white matter diseases using magnetic resonance based techniques. Journal of Neurology 248, 1019-1029.

Folstein, M.F., Folstein, S.E., McHugh, P.R., 1975. “Mini-mental state”. A practical method for grading the cognitive state of patients for the clinician. Journal of Psychiatric Research 12, 189-198.

Goodwin, G.M., 1997. Neuropsychological and neuroimaging evidence for the involvement of the frontal lobes in depression. Journal of Psychopharmacology $11,115-122$.

Gouw, A.A., Seewann, A., Vrenken, H., van der Flier, W.M., Rozemuller, J.M., Barkhof, F. Scheltens, P., Geurts, J.J., 2008. Heterogeneity of white matter hyperintensities in Alzheimer's disease: post-mortem quantitative MRI and neuropathology. Brain 131, 3286-3298.

Greenwald, B.S., Kramer-Ginsberg, E., Krishnan, K.R., Ashtari, M., Auerbach, C., Patel, M., 1998. Neuroanatomic localization of magnetic resonance imaging signal hyperintensities in geriatric depression. Stroke 29, 613-617.

Gunning-Dixon, F.M., Hoptman, M.J., Lim, K.O., Murphy, C.F., Klimstra, S., Latoussakis, V. Majcher-Tascio, M., Hrabe, J., Ardekani, B.A., Alexopoulos, G.S., 2008. Macromolecular white matter abnormalities in geriatric depression: a magnetization transfer imaging study. The American Journal of Geriatric Psychiatry 16, 255-262.

Gutman, D.A., Holtzheimer, P.E., Behrens, T.E., Johansen-Berg, H., Mayberg, H.S., 2009. A tractography analysis of two deep brain stimulation white matter targets for depression. Biological Psychiatry 65, 276-282.

Haggard, P., 2008. Human volition: towards a neuroscience of will. Nature Reviews. Neuroscience 9, 934-946.

Heimer, L., 1995. The Human Brain and Spinal Cord: Functional Neuroanatomy and Dissection Guide, 2. ed. Springer-Verlag, New York.

Henkelman, R.M., Stanisz, G.J., Graham, S.J., 2001. Magnetization transfer in MRI: a review. NMR in Biomedicine 14, 57-64.

Herrmann, L.L., Goodwin, G.M., Ebmeier, K.P., 2007. The cognitive neuropsychology of depression in the elderly. Psychological Medicine 37, 1693-1702. 
Herrmann, L.L., Le Masurier, M., Ebmeier, K.P., 2008. White matter hyperintensities in late life depression: a systematic review. Journal of Neurology, Neurosurgery and Psychiatry 79, 619-624.

Hickie, I., Scott, E., Mitchell, P., Wilhelm, K., Austin, M.P., Bennett, B., 1995. Subcortica hyperintensities on magnetic resonance imaging: clinical correlates and prognostic significance in patients with severe depression. Biological Psychiatry $37,151-160$.

Hickie, I., Scott, E., Wilhelm, K. Brodaty, H., 1997. Subcortical hyperintensities on magnetic resonance imaging in patients with severe depression-a longitudinal evaluation. Biological Psychiatry 42, 367-374

Iosifescu, D.V., Renshaw, P.F., Lyoo, I.K., Lee, H.K., Perlis, R.H., Papakostas, G.I., Nierenberg, A.A., Fava, M., 2006. Brain white-matter hyperintensities and treatment outcome in major depressive disorder. The British Journal of Psychiatry $188,180-185$.

Jane-Llopis, E., Matytsina, I., 2006. Mental health and alcohol, drugs and tobacco: review of the comorbidity between mental disorders and the use of alcohol, tobacco and illicit drugs. Drug and Alcohol Review 25, 515-536.

Johansen-Berg, H., Gutman, D.A., Behrens, T.E., Matthews, P.M., Rushworth, M.F., Katz E., Lozano, A.M., Mayberg, H.S., 2008. Anatomical connectivity of the subgenual cingulate region targeted with deep brain stimulation for treatment-resistant depression. Cerebral Cortex 18, 1374-1383.

Jones, D.K., 2004. The effect of gradient sampling schemes on measures derived from diffusion tensor MRI: a Monte Carlo study. Magnetic Resonance in Medicine 51, 807-815.

Jones, D.K., Williams, S.C., Gasston, D., Horsfield, M.A., Simmons, A., Howard, R., 2002 Isotropic resolution diffusion tensor imaging with whole brain acquisition in clinically acceptable time. Human Brain Mapping 15, 216-230.

Kim, K.W., MacFall, J.R., Payne, M.E., 2008. Classification of white matter lesions on magnetic resonance imaging in elderly persons. Biological Psychiatry 64, 273-280.

Krishnan, K.R., McDonald, W.M., 1995. Arteriosclerotic depression. Medical Hypotheses $44,111-115$

Krishnan, K.R., Hays, J.C., Blazer, D.G., 1997. MRI-defined vascular depression. The American Journal of Psychiatry 154, 497-501.

Krishnan, M.S., O'brien, J.T., Firbank, M.J., Pantoni, L., Carlucci, G., Erkinjuntti, T., Wallin, A., Wahlund, L.O., Scheltens, P., van Straaten, E.C., Inzitari, D., 2006. Relationship between periventricular and deep white matter lesions and depressive symptoms in older people. The LADIS Study. International Journal of Geriatric Psychiatry 21, 983-989.

Kumar, A., Gupta, R.C., Albert, T.M., Alger, J., Wyckoff, N., Hwang, S., 2004. Biophysical changes in normal-appearing white matter and subcortical nuclei in late-life major depression detected using magnetization transfer. Psychiatry 130, 131-140.

Le Bihan, D., 2003. Looking into the functional architecture of the brain with diffusion MRI. Nature Reviews. Neuroscience 4, 469-480.

Le Bihan, D., Mangin, J.F., Poupon, C., Clark, C.A., Pappata, S., Molko, N., Chabriat, H., 2001. Diffusion tensor imaging: concepts and applications. Journal of Magnetic Resonance Imaging 13, 534-546.

Liao, D., Cooper, L., Cai, J., Toole, J., Bryan, N., Burke, G., Shahar, E., Nieto, J., Mosley, T., Heiss, G., 1997. The prevalence and severity of white matter lesions, thei relationship with age, ethnicity, gender, and cardiovascular disease risk factors: the ARIC Study. Neuroepidemiology 16, 149-162.

Longstreth Jr., W.T., Arnold, A.M., Beauchamp Jr., N.J., Manolio, T.A., Lefkowitz, D. Jungreis, C., Hirsch, C.H., O'Leary, D.H., Furberg, C.D., 2005. Incidence, manifestations, and predictors of worsening white matter on serial cranial magnetic resonance imaging in the elderly: the Cardiovascular Health Study. Stroke 36, 56-61.

MacFall, J.R., Payne, M.E., Provenzale, J.E., Krishnan, K.R., 2001. Medial orbital frontal lesions in late-onset depression. Biological Psychiatry 49, 803-806.

Makris, N., Kennedy, D.N., McInerney, S., Sorensen, A.G., Wang, R., Caviness Jr., V.S., Pandya, D.N., 2005. Segmentation of subcomponents within the superior longitudinal fascicle in humans: a quantitative, in vivo, DT-MRI study. Cerebral Cortex 15 854-869.

Mayberg, H.S., 1997. Limbic-cortical dysregulation: a proposed model of depression1 The Journal of Neuropsychiatry and Clinical Neurosciences 9, 471-481.

Mazziotta, J., Toga, A., Evans, A., Fox, P., Lancaster, J., Zilles, K., Woods, R., Paus, T Simpson, G., Pike, B., Holmes, C., Collins, L., Thompson, P., MacDonald, D., Iacoboni, M., Schormann, T., Amunts, K., Palomero-Gallagher, N., Geyer, S., Parsons, L., Narr K., Kabani, N., Le Goualher, G., Boomsma, D., Cannon, T., Kawashima, R., Mazoyer, B. 2001. A probabilistic atlas and reference system for the human brain: International Consortium for Brain Mapping (ICBM). Philosophical Transactions of the Royal Society B. Biological Sciences 356, 1293-1322.

McGill, R., Tukey, J.W., Larsen, W.A., 1978. Variations of Box Plots. The American Statistician 32, 12-16.

Moller, M., Frandsen, J., Andersen, G., Gjedde, A., Vestergaard-Poulsen, P., Ostergaard, L. 2007. Dynamic changes in corticospinal tracts after stroke detected by fibretracking. Journal of Neurology, Neurosurgery and Psychiatry 78, 587-592.

Mori, S., van Zijl, P.C., 2002. Fiber tracking: principles and strategies - a technical review. NMR in Biomedicine 15, 468-480.

Mori, S., Crain, B.J., Chacko, V.P., van Zijl, P.C., 1999. Three-dimensional tracking of axona projections in the brain by magnetic resonance imaging. Annals of Neurology 45 , 265-269.

Mori, S., Wakana, S., Van Zijl, P.C.M., 2005. MRI Atlas of Human White Matter, 1. ed. Elsevier, Amsterdam.

Nobuhara, K., Okugawa, G., Sugimoto, T., Minami, T., Tamagaki, C., Takase, K., Saito, Y., Sawada, S., Kinoshita, T., 2006. Frontal white matter anisotropy and symptom severity of late-life depression: a magnetic resonance diffusion tensor imaging study. Journal of Neurology, Neurosurgery and Psychiatry 77, 120-122.
O'Brien, J., Desmond, P., Ames, D., Schweitzer, I., Harrigan, S., Tress, B., 1996. A magnetic resonance imaging study of white matter lesions in depression and Alzheimer's disease. The British Journal of Psychiatry 168, 477-485.

O'Brien, J., Ames, D., Chiu, E., Schweitzer, I., Desmond, P., Tress, B., 1998. Severe deep white matter lesions and outcome in elderly patients with major depressive disorder: follow up study. BMJ 317, 982-984.

O'Brien, J.T., Firbank, M.J., Krishnan, M.S., van Straaten, E.C., van der Flier, W.M., Petrovic, K., Pantoni, L., Simoni, M., Erkinjuntti, T., Wallin, A., Wahlund, L.O., Inzitari, D., 2006. White matter hyperintensities rather than lacunar infarcts are associated with depressive symptoms in older people: the LADIS study. The American Journal of Geriatric Psychiatry 14, 834-841.

Oldfield, R.C., 1971. The assessment and analysis of handedness: the Edinburgh inventory. Neuropsychologia 9, 97-113.

Pantoni, L., Garcia, J.H., 1995. The significance of cerebral white matter abnormalities 100 years after Binswanger's report. A review. Stroke 26, 1293-1301.

Pardo, J.V., Fox, P.T., Raichle, M.E., 1991. Localization of a human system for sustained attention by positron emission tomography. Nature 349, 61-64.

Paul, R.H., Grieve, S.M., Niaura, R., David, S.P., Laidlaw, D.H., Cohen, R., Sweet, L., Taylor, G., Clark, R.C., Pogun, S., Gordon, E., 2008. Chronic cigarette smoking and the microstructural integrity of white matter in healthy adults: a diffusion tensor imaging study. Nicotine \& Tobacco Research 10, 137-147.

Pierpaoli, C., Jezzard, P., Basser, P.J., Barnett, A., Di, C.G., 1996. Diffusion tensor MR imaging of the human brain. Radiology 201, 637-648.

Robbins, S., Evans, A.C., Collins, D.L., Whitesides, S., 2004. Tuning and comparing spatial normalization methods. Medical Image Analysis 8, 311-323.

Schmierer, K., Scaravilli, F., Altmann, D.R., Barker, G.J., Miller, D.H., 2004. Magnetization transfer ratio and myelin in postmortem multiple sclerosis brain. Annals of Neurology 56, 407-415.

Sexton, C.E., Mackay, C.E., Ebmeier, K.P., 2009. A systematic review of diffusion tensor imaging studies in affective disorders. Biological Psychiatry 66, 814-823.

Sheline, Y.I., Barch, D.M., Garcia, K., Gersing, K., Pieper, C., Welsh-Bohmer, K., Steffens, D.C., Doraiswamy, P.M., 2006. Cognitive function in late life depression: relationships to depression severity, cerebrovascular risk factors and processing speed. Biological Psychiatry 60, 58-65.

Sheline, Y.I., Price, J.L., Vaishnavi, S.N., Mintun, M.A., Barch, D.M., Epstein, A.A., Wilkins, C.H., Snyder, A.Z., Couture, L., Schechtman, K., McKinstry, R.C., 2008. Regional white matter hyperintensity burden in automated segmentation distinguishes late-life depressed subjects from comparison subjects matched for vascular risk factors. The American Journal of Psychiatry 165, 524-532.

Shimony, J.S., Sheline, Y.I., D'Angelo, G., Epstein, A.A., Benzinger, T.L., Mintun, M.A., McKinstry, R.C., Snyder, A.Z., 2009. Diffuse microstructural abnormalities of normal-appearing white matter in late life depression: a diffusion tensor imaging study. Biological Psychiatry 66, 245-252.

Simpson, S., Baldwin, R.C., Jackson, A., Burns, A.S., 1998. Is subcortical disease associated with a poor response to antidepressants? Neurological, neuropsychological and neuroradiological findings in late-life depression. Psychological Medicine 28, 1015-1026.

Spilt, A., Goekoop, R., Westendorp, R.G., Blauw, G.J., de Craen, A.J., van Buchem, M.A., 2006. Not all age-related white matter hyperintensities are the same: a magnetization transfer imaging study. AJNR. American Journal of Neuroradiology 27, 1964-1968.

Steffens, D.C., Conway, C.R., Dombeck, C.B., Wagner, H.R., Tupler, L.A., Weiner, R.D., 2001. Severity of subcortical gray matter hyperintensity predicts ECT response in geriatric depression. The Journal of ECT 17, 45-49.

Steffens, D.C., Bosworth, H.B., Provenzale, J.M., MacFall, J.R., 2002. Subcortical white matter lesions and functional impairment in geriatric depression. Depression and Anxiety $15,23-28$

Steffens, D.C., Potter, G.G., McQuoid, D.R., MacFall, J.R., Payne, M.E., Burke, J.R., Plassman, B.L., Welsh-Bohmer, K.A., 2007. Longitudinal magnetic resonance imaging vascular changes, apolipoprotein $\mathrm{E}$ genotype, and development of dementia in the neurocognitive outcomes of depression in the elderly study. The American Journal of Geriatric Psychiatry 15, 839-849.

Tanabe, J.L., Ezekiel, F., Jagust, W.J., Reed, B.R., Norman, D., Schuff, N., Weiner, M.W., Chui, H., Fein, G., 1999. Magnetization transfer ratio of white matter hyperintensities in subcortical ischemic vascular dementia. AJNR. American Journal of Neuroradiology 20, 839-844.

Taylor, W.D., Payne, M.E., Krishnan, K.R., Wagner, H.R., Provenzale, J.M., Steffens, D.C. MacFall, J.R., 2001. Evidence of white matter tract disruption in MRI hyperintensities. Biological Psychiatry 50, 179-183.

Taylor, W.D., MacFall, J.R., Steffens, D.C., Payne, M.E., Provenzale, J.M., Krishnan, K.R., 2003a. Localization of age-associated white matter hyperintensities in late-life depression. Progress in Neuro-Psychopharmacology and Biological Psychiatry 27, 539-544.

Taylor, W.D., Steffens, D.C., MacFall, J.R., McQuoid, D.R., Payne, M.E., Provenzale, J.M., Krishnan, K.R., 2003b. White matter hyperintensity progression and late-life depression outcomes. Archives of General Psychiatry 60, 1090-1096.

Taylor, W.D., MacFall, J.R., Payne, M.E., McQuoid, D.R., Provenzale, J.M., Steffens, D.C., Krishnan, K.R., 2004. Late-life depression and microstructural abnormalities in dorsolateral prefrontal cortex white matter. The American Journal of Psychiatry $161,1293-1296$.

Taylor, W.D., Bae, J.N., MacFall, J.R., Payne, M.E., Provenzale, J.M., Steffens, D.C., Krishnan, K.R., 2007. Widespread effects of hyperintense lesions on cerebral white matter structure. AJR. American Journal of Roentgenology 188, 1695-1704.

Taylor, W.D., Kuchibhatla, M., Payne, M.E., MacFall, J.R., Sheline, Y.I., Krishnan, K.R., Doraiswamy, P.M., 2008. Frontal white matter anisotropy and antidepressant remission in late-life depression. PLoS ONE 3, e3267. 
Theobald, M.R., Muro, G.J., Karis, J.P., 2000. The aging brain and neurodegenerative disorders. In: Orrison Jr., W.W. (Ed.), Neuroimaging. W.B. Saunders Company, Philadelphia, pp. 829-852.

Thomas, A.J., O'brien, J.T., Davis, S., Ballard, C., Barber, R., Kalaria, R.N., Perry, R.H., 2002. Ischemic basis for deep white matter hyperintensities in major depression: a neuropathological study. Archives of General Psychiatry 59, 785-792.

Thomas, A.J., O'brien, J.T., Barber, R., McMeekin, W., Perry, R., 2003. A neuropathological study of periventricular white matter hyperintensities in major depression. Journal of Affective Disorders 76, 49-54.

Tofts, P.S., Steens, S.C.A., van Buchem, M.A., 2003. MT: magnetization transfer. In: Tofts, P. (Ed.), Quantitative MRI of the Brain: Measuring Changes Caused by Disease. John Wiley Sons Ltd., Chichester, West Sussex, England, pp. 257-298.

van Waesberghe, J.H., Kamphorst, W., De Groot, C.J., van Walderveen, M.A., Castelijns, J.A., Ravid, R., Nijeholt, G.J., van der Valk, P, Polman, C.H., Thompson, A.J., Barkhof, F., 1999. Axonal loss in multiple sclerosis lesions: magnetic resonance imaging insights into substrates of disability. Annals of Neurology 46, 747-754.

Videbech, P., 1997. MRI findings in patients with affective disorder: a meta-analysis. Acta Psychiatrica Scandinavica 96, 157-168.

Videbech, P., Ravnkilde, B., Gammelgaard, L., Egander, A., Clemmensen, K., Rasmussen, N.A., Gjedde, A., Rosenberg, R., 2004. The Danish PET/depression project: performance on Stroop's test linked to white matter lesions in the brain. Psychiatry $130,117-130$.

Wing, J.K., Sartorius, N., Üstün, T.B., 1998. Diagnosis and Clinical Measurement in 997 Psychiatry. A Reference Manual for SCAN. Cambridge University Press, Cambridge, A reference manual for SCAN.

Wolf, P.A., D'Agostino, R.B., Belanger, A.J., Kannel, W.B., 1991. Probability of stroke: a risk profile from the Framingham Study. Stroke 22, 312-318.

World Health Organization, 1993. The ICD-10 Classification of Mental and Behavioural Disorders. Diagnostic Criteria for Research, World Health Organization, Geneva.

World Medical Association, 2008. Declaration of Helsinki. Web/URL: http://www.wma net/e/policy/b3.htm.

Worsley, K.J., Marrett, S., Neelin, P., Vandal, A.C., Friston, K.J., Evans, A.C., 1996. A unified statistical approach for determining significant signals in images of cerebral activation. Human Brain Mapping 4, 58-73.

Worsley, K.J., Liao, C.H., Aston, J., Petre, V., Duncan, G.H., Morales, F., Evans, A.C., 2002. A general statistical analysis for fMRI data. Neuroimage 15, 1-15.

Yang, Q., Huang, X., Hong, N., Yu, X., 2007. White matter microstructural abnormalities in late-life depression. International Psychogeriatrics 19, 757-766.

Yuan, Y., Zhang, Z., Bai, F., Yu, H., Shi, Y., Qian, Y., Zang, Y., Zhu, C., Liu, W., You, J., 2007 White matter integrity of the whole brain is disrupted in first-episode remitted geriatric depression. NeuroReport 18, 1845-1849. 